\title{
Tree canopy affects soil macrofauna spatial patterns on broad- and meso- scale levels in an Eastern European poplar-willow forest in the floodplain of the River Dnipro
}

\author{
Oleksandr V. Zhukov*, Olga M. Kunah, Yuliya Y. Dubinina, Marina P. Fedushko, \\ Vadim I. Kotsun, Yuliya O. Zhukova, Olena V. Potapenko
}

Department of Zoology and Ecology, Faculty of Biology and Ecology, Oles Honchar Dnipro National University, Gagarin Ave. 72, Dnipro, 49010, Ukraine

\begin{abstract}
Zhukov, O.V., Kunah, O.M., Dubinina, Y.Y., Fedushko, M.P., Kotsun, V.I., Zhukova, Y.O., Potapenko, O.V., 2019. Tree canopy affects soil macrofauna spatial patterns on broad- and meso-scale levels in an Eastern European poplar-willow forest in the floodplain of the River Dnipro. Folia Oecologica, 46: 101-114.

This paper tested the hypothesis that the placement of trees in the floodplain ecosystem leads to multiscale spatial structuring and plays an important role in formation of the spatial patterns of the soil macrofauna. The research polygon was laid in an Eastern European poplar-willow forest in the floodplain of the River Dnipro. The litter macrofauna was manually collected from the soil samples. The distances of the sampling locations from the nearest individual of each tree species were applied to obtain a measure of the overstorey spatial structure. The pure effect of tree structured space on the soil animal community was presented by the broad-scale and meso-scale components. The soil animal community demonstrated patterns varying in tree structured space. The tree induced spatial heterogeneity was revealed to effect on the vertical stratification of the soil animal community. The complex nature of the soil animal community variability depending on the distance from trees was depended on the interaction of tree species in their effects on soil animals. The importance of the spatial structures that interact with soil, plants and tree factors in shaping soil macrofauna communities was shown.
\end{abstract}

Keywords

ecological groups, environmental factors, neutral diversity, soil macrofauna, spatial variation, tree canopy

\section{Introduction}

The environmental control on species distribution according to the niche theory will result in the variation of species composition explained by environmental variables (CHANG et al., 2013). Abiotic processes are generally considered as environmental filters, which select those species that match the specific habitat requirements (Lososoví et al., 2015). The non-environmental factors such as disper- sal and other population processes have been shown as being important in community structuring (LEGENDRE et al., 2005). Dispersal is the probability that a given patch will be colonized (KING and WITH, 2002). The dispersal limitation and/or ecological drift have been revealed to be important as factors responsible for soil community assembly (Bahram et al., 2016; Dumbrell et al., 2010; PeaY et al., 2010; Powell et al., 2015; StegEn et al., 2012). The dispersal limitation is considered as being able to generate

*Corresponding author:

e-mail: zhukov_dnipro@ukr.net 
spatial patterns in community structure that are detectable by spatial filters (CHANG et al., 2013). Community composition and species distribution would be spatially structured independent of environment if dispersal limitation was a major assembly process (JonES et al., 2006; AIBA et al., 2012). The assumption that the pure spatial component represents the role of dispersal limitation holds only in cases where all relevant environmental variables are considered (CHANG et al., 2013). The impact of environmental factors has been shown to increase as the spatial scale increases, due to the inclusion of greater environmental heterogeneity (BARTON et al., 2013; CHASE, 2014; DE CÁCEREs et al., 2012; Dini-ANDREOTE et al., 2015).

The soil biota is structured by abiotic and/or biotic forces (e.g., competition, predation) (SCHEU and SchaEFER, 1998). Animal communities may be controlled from the bottom via shortage of resources or from the top via predators (Hunter and Price, 1992; Power, 1992). In many investigations, soil communities are considered to be driven by environmental selection (BARDGETT and van der Putten, 2014; Hanson et al., 2012; IgOndová and MajZlan, 2015). The soil macrofauna communities respond to two main environmental factors: the structure of the vegetation and the quality of above-ground litter (DECAENs et al., 1998). The edaphic and plant factors have been revealed to play an important role in structuring the communities of soil macrofauna on the level of beta diversity (ZHUKOv et al., 2018b). The soil-pore-size distribution, soil microclimate, root structure and above-ground vegetation structure result in the small-scale of the soil fauna's patch distribution (VIKETOFT, 2013). Soil animal communities are directly influenced by vegetation through litter and roots (Ponsard et al., 2000; Mitchell et al., 2007). Densities of soil biota have been shown to increase generally with increasing plant cover and litter input (Frouz et al., 2008). Plants modify the microclimate in their vicinity by cooling down the soil and air in the shade of their leaves (MATHIEU et al., 2009). Environmental conditions, such as gradients in soil $\mathrm{pH}$, soil moisture and vegetation composition have a large impact on soil organism distributions (SAETre, 1999; Jimenez et al., 2006). But no statistically significant relationship was found between the occurrence of epigeic macrofauna and the microclimate of the studied forest stands (Lazorík and Kula, 2015). The plants modify food quality, quantity, and the microclimate of the soil macrofauna (MATHIEU et al., 2009).

Tree density and diversity could be the key drivers of the spatial patterning of soil macrofauna diversity (GHOLAMI et al., 2017). Tree diversity can increase earthworm community diversity by the mechanism of creating small scale microhabitat diversity (CESARZ et al., 2007). Forest vegetation favours litter-dwelling macroarthropods (CALLAHAM et al., 2006). The shading effect of trees, the lower soil temperature, and higher soil moisture creates favourable conditions for higher abundance of earthworms (TIAN et al., 2000). The structure of the vegetation determines the diversity of microhabitats and life conditions for macroinvertebrates. The above-ground litter production depends on the nature of the vegetation (DECAENS et al., 1998). The plant diversity may increase soil fauna diversity due to the fact that soil animals make a complementary use of the different types of litter (HoOPER et al., 2000). Grassy vegetation favours the abundance and species richness of soil-dwelling animals such as earthworms (GRAEFE and BEYLICH, 2003). Plant biomass and primary production are often supposed to have a direct bottom-up positive effect on soil fauna density that is independent of plant diversity (CHEN and Wise, 1999; HoOPER et al., 2000)

In this study, we aimed to: i) estimate proportional input of soil structure, composition of herb community and spatial factors to structuring of soil macrofauna communities, ii) test the hypothesis that the placement of trees in the floodplain ecosystem leads to multiscale spatial structuring and plays an important role in formation of the soil macrofauna spatial patterns, iii) test the hypothesis that vertical stratification of the soil animal community is sensitive to the tree induced spatial variability.

\section{Methods}

\section{Site description}

The research was carried out in May 2018 in the "Dniprovsko-Orilsky" Nature Reserve. The research polygon (48 30 '51'N, 3449'02'E) was laid in an Eastern European poplar-willow forest in the floodplain of the River Protich, which is a left inflow of the River Dnipro. The study site comprises 1.0 ha of deciduous woodland bordered by arena terrace above the floodplain of the River Dnipro. Forests in the steppe zone of Ukraine have a very restricted distribution and usually have an island status. The soils are fertile sandy loam, the underlying geology comprises Quaternary Aeolian sandy sediments. The territory has a temperate-continental climate with an annual mean maximum decade temperature of $25.7{ }^{\circ} \mathrm{C}$, and a minimum of $-10.0{ }^{\circ} \mathrm{C}$, and with a mean annual precipitation of approximately $565 \mathrm{~mm}$ (20 year average according to data of the Dnipro meteorological station).

\section{Sampling methods}

The polygon consisted of 7 transects. Each transect was made up of 15 sampling points. The distance between rows within the polygon was $3 \mathrm{~m}$ (ZHUKOV et al., 2018a). Soil macrofauna was defined as an invertebrate group found within terrestrial soil samples which has more than $90 \%$ of its specimens in such samples visible to the naked eye (macroscopic organisms) (WARREN and Zou, 2002; LAVELle et al., 2003; GHOLAMI, 2016). Geobionts (large soil invertebrates that permanently inhabit the soil) and geophiles (organisms that live in the soil only for particular phases of their lives) (KrivolutsKy, 1992; GHOLAmi et al., 2016) were assessed. Samples consisted of single blocks of soil, $25 \times 25 \times 30 \mathrm{~cm}^{3}$ deep, dug out quickly. A quadrat was fixed on the soil surface prior to taking the 
soil samples. The litter macrofauna was manually collected from the soil samples. The soil macrofauna were sorted and the animals were stored in $4 \%$ formaldehyde (MAthieu et al., 2004; Zhukov et al., 2018a).

\section{Vegetation survey and plant variables}

Vascular plant species lists were recorded for each $3 \times 3$ $\mathrm{m}$ subplot along with visual estimates of species cover using the nine-degree Braun-Blanquet scale (WESTHOFF and VAN DER MAAREL, 1978). The projective cover of plant species was recorded at ground level, the understorey (up to $2 \mathrm{~m}$ height) and canopy (above $2 \mathrm{~m}$ height). We were able to make species level identification for all quadrats. Seedlings and saplings of woody species were later excluded from the analyses. Within the plot, all woody stems $\geq 1 \mathrm{~cm}$ in diameter at breast height were measured and mapped.

In syntaxonomic aspect the vegetation can be identified as follows: Class Salicetea purpureae Moor 1958, Ordo Salicetalia purpureae Moor 1958, Union Salicion albae R.Tx. 1955, Ass. Populetum albae Br.-B1.1931

Based on geobotanical descriptions, phytoindicative assessment of environmental factors according to DiDUKH (2011) was made. Didukh phytoindication scales (DIDUKH, 2011) include edaphic and climatic scales. The edaphic phytoindication scales include the soil water regime (Hd), the variability of humidity $(\mathrm{fH})$, the soil aeration (Ae), the soil acidity (Rc), the total salt regime $(\mathrm{Sl})$, the carbonate content in the soil $(\mathrm{Ca})$ and nitrogen content in the soil $(\mathrm{Nt})$. The climatic scales include the parameters of the thermal climate (thermal regime, Tm), humidity $(\mathrm{Om})$, cryo-climate $(\mathrm{Cr})$ and the continentality of climate $(\mathrm{Kn})$. In addition to these, the lighting scale (Lc) is indicated, which is characterized as a microclimate scale. Thermal properties of the soils are indicated by the thermal regime scale, and the hydrothermal properties by the ombro regime scale (ZHukov et al., 2018a). Phytoindicational assessment of environmental factors was performed by the ideal indicator method of BuzuK (2017).

\section{Soil variables}

Measurement of soil mechanical impedance was carried out in the field using a hand penetrometer Eijkelkamp, to a depth of $100 \mathrm{~cm}$ at intervals of $5 \mathrm{~cm}$. The average error of the measurement results of the device is $\pm 8 \%$. The measurements were made by a cone with a cross-sectional dimension of $2 \mathrm{~cm}^{2}$. Within each measurement point, the mechanical impedance of the soil was made in a single replication. To measure the electrical conductivity of the soil in situ, the sensor HI 76305 was used (Hanna Instruments, Woonsocket, R. I.). This sensor works in conjunction with the portable device HI 993310. Soil temperature was measured from 1 to $2 \mathrm{pm}$ by digital thermometers WT-1 (PJSC “Steklopribor", http://bit.steklopribor.com, to $0.1{ }^{\circ} \mathrm{C}$ accuracy) at a depth of 5-7 $\mathrm{cm}$. Temperature measurements were made in triplicate at each test point.
The aggregate structure was evaluated by Savinov's dry sieving method (VADUnina and Korchagina, 1986). The percentage content of such fractions was established: $<0.25,0.25-0.5,0.5-1,1-2,2-3,3-5,5-7,7-10,>10 \mathrm{~mm}$, and plant roots. The bulk density of the soil was estimated by the Kachinskiy method, soil moisture by the weight method (VAdunina and Korchagina, 1986; Zhukov et al., 2018a).

\section{Statistical analysis}

Redundancy analysis (RDA) was used for analysis of the variance both in herb layer and soil macrofauna species composition (RAO, 1964). Before the analyses, percentage cover of plant species or abundance of animal species was Hellinger transformed to avoid problematic Euclidean distances used in the RDA (LEGENDRE and GALlaGHER, 2001). Soil mechanical impedance, soil electrical conductivity, litter layer thickness, soil temperature, moisture and soil bulk density were log transformed. The axes extracted after redundancy analysis of the herb layer community were used as constrained for soil macrofauna ordination procedure. Phytoindication estimation of the ecological factors (DIDUKH, 2011) was used to find an ecological interpretation of the plant community ordination axes.

The significance of RDA global model was first tested. The soil and plant models were based on the forward selection of soil plant variables and were built with double stopping rule (alpha significance level and the $R^{2}{ }_{a d j}$ calculated using all explanatory variables) (BLANCHET et al., 2008). Variables were retained only with a significant relationship to community composition $(p<0.05,9999$ permutations). The models' marginal effect was computed, in which each selected soil or plant variable was used separately as a predictor of community composition and the significance of all the models was tested and $R^{2}{ }_{a d j}$ was extracted.

The geographic coordinates of sampling locations were used to generate a set of orthogonal eigenvectorbased spatial variables (dbMEMs), each of them representing a pattern of particular scale within the extent of the sampling area (BORCARD and LEGENDRE, 2002). The forward-selection procedure on partial RDAs was applied to the subset of spatial variables. The significance of soil models was tested by the Monte Carlo permutation test (9999 permutations).

The distances of the soil sampling locations from the nearest individual of each tree species were applied as a measure of the overstorey spatial structure. The distance matrix of sampling locations was calculated, which provided the opportunity to generate eigenvector-based spatial variables (dbMEMs-tree based). The forward-selection procedure on partial RDAs was applied to the subset of tree-structured spatial variables and the significance of models was tested by the Monte Carlo permutation test (9999 permutations).

In the next phase of the study, the dbMEMs were forward-selected directly on community data to explore 
patterns in community variation by variance partitioning between environmental and spatial influence. The significance of pure spatial and environmental fractions was tested by Monte Carlo permutation tests with 9999. The scalogram approach was applied to inspect in detail the spatial scaling of community variation (LEGENDRE and LEGENDRE, 2012). To do this, the two sets of RDA analyses were carried out with each of the dbMEM variables as a predictor. As a response variable, the first set of RDA analyses used raw (Hellinger-transformed) species data, while the second set used residuals of the environmental model in which forward-selected environmental variables acted as predictors (Chudomelova et al., 2017). From each RDA we extracted $R^{2}$ adj for individual dbMEMs and plotted them into juxtaposed barplots (CHANG et al., 2013).

All statistical analyses were conducted in R (v. 3.5.0., $\mathrm{R}$ Foundation for Statistical Computing, Vienna, AT), using the following packages: vegan (v. 2.5-2, https:// CRAN.R-project.org/package=vegan) for the multivariate analysis and for the computation of global and partial Moran's I. (OKSANEN et al., 2018), adespatial (v. 0.3-2. https:// CRAN.R-project.org/package=adespatial) for the forward selection and for the generation of spatial filters (DRAY et al., 2018).

\section{Results}

During manual sorting of the soil samples, 29 species of soil animals were found. The density of the soil macrofauna of the polygon was $91.4 \pm 20.2 \mathrm{ind} . / \mathrm{m}^{2}$. The dominant group was larvae of the insects, which averaged $63.7 \%$ of the total community abundance and presented by 19 species including dominant Serica brunnea (Linnaeus, 1758). The family Elateridae was the most diverse among soil dwelling insect larvae. Earthworms (Lumbric- idae) averaged $33.5 \%$ of the total community abundance. Earthworms were represented by four species: two endogeic species Aporrectodea caliginosa trapezoides (Duges, 1828) and Aporrectodea rosea rosea (Savigny, 1826), one anecic species Octodrilus transpadanus (Rosa, 1884), and one amphibiont species Eiseniella tetraedra tetraedra (Savigny, 1826).

The forest overstorey included Populus alba L. (41.5\% of total tree stems), Ulmus laevis Pall (40.7\%), and Crataegus fallacina Klokov (4.4\%). There were dead trees within the site (13.3\%) (Fig. 1). The average distance from the sampling locations to the nearest Populus alba stems was $2.0 \pm 0.094 \mathrm{~m}$ (maximum $-4.6 \mathrm{~m})$, to Ulmus laevis stems $2.3 \pm 0.13 \mathrm{~m}$ (maximum - 7.6 m), to Crataegus fallacina stems $12.8 \pm 0.81 \mathrm{~m}$ (maximum $-30.6 \mathrm{~m}$ ), and to dead stems $3.8 \pm 0.19 \mathrm{~m}$ (maximum $-9.1 \mathrm{~m})$.

The plant community data (considering Hellingerstandardized species data) were subjected to ordination procedure by redundancy analysis, as a result of which the 6 principal components were extracted (Table 1). These principal components explained $57 \%$ of the plant community variation. The principal components can be interpreted by comparison with environmental factors derived from phytoindication assessment. The correlation analysis revealed that the principal component 1 reflects the variation of plant community due to soil total salt regime gradient. The principal component 2 reflected the opposite correlation between soil humidity and aeration. The principal component 3 was sensitive to climatic regimes. The principal component 4 reflected variations in the nitrogen content as well as some climate regimes. The principal component 5 indicated an inverse dependence of variability of moisture and carbonate content in the soil. The principal component 6 was a marker of the acidity gradient. The extracted principal components were used as markers of the herb layer species community in further analysis.

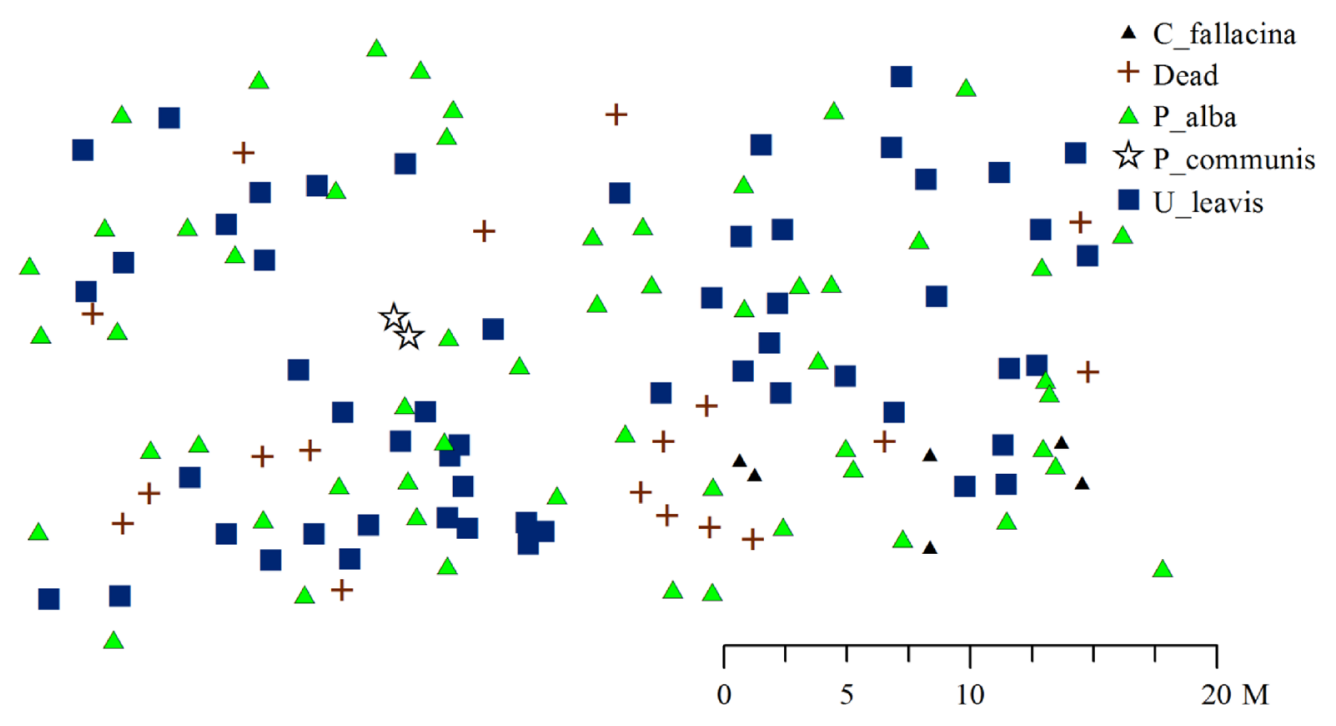

Fig. 1. Spatial locations of the tree species individuals within the site. 
Table 1. Fitting phytoindication values onto the plant community ordination (only significant correlation coefficients are presented, $p<0.05$ )

\begin{tabular}{|c|c|c|c|c|c|c|c|c|}
\hline \multirow{3}{*}{ Predictors } & \multicolumn{6}{|c|}{ Principal components and proportion of the variation explained } & \multirow{3}{*}{$R^{2}$} & \multirow{3}{*}{$\operatorname{Pr}(>r)$} \\
\hline & $\mathrm{PC} 1$ & $\mathrm{PC} 2$ & PC3 & PC4 & PC5 & PC6 & & \\
\hline & 0.18 & 0.11 & 0.08 & 0.07 & 0.07 & 0.06 & & \\
\hline $\mathrm{Hd}$ & -0.67 & 0.69 & - & - & - & - & 0.42 & 0.001 \\
\hline $\mathrm{fH}$ & - & -0.56 & - & - & -0.76 & - & 0.27 & 0.001 \\
\hline $\mathrm{Rc}$ & 0.74 & - & - & - & - & -0.55 & 0.29 & 0.001 \\
\hline $\mathrm{S} 1$ & 0.97 & - & - & - & - & - & 0.44 & 0.001 \\
\hline $\mathrm{Ca}$ & - & - & - & - & 0.69 & -0.32 & 0.12 & 0.051 \\
\hline $\mathrm{Nt}$ & -0.39 & -0.49 & - & -0.72 & - & - & 0.42 & 0.001 \\
\hline $\mathrm{Ae}$ & 0.36 & -0.80 & - & 0.32 & -0.36 & - & 0.39 & 0.001 \\
\hline $\mathrm{Tm}$ & - & -0.43 & - & 0.87 & - & - & 0.40 & 0.001 \\
\hline $\mathrm{Om}$ & - & -0.77 & 0.53 & - & - & - & 0.26 & 0.001 \\
\hline $\mathrm{Kn}$ & - & - & -0.85 & -0.46 & - & - & 0.22 & 0.001 \\
\hline $\mathrm{Cr}$ & 0.55 & - & - & 0.71 & -0.42 & - & 0.48 & 0.001 \\
\hline $\mathrm{Lc}$ & -0.53 & -0.72 & - & 0.40 & - & - & 0.38 & 0.001 \\
\hline
\end{tabular}

$\mathrm{Hd}$, soil humidity; $\mathrm{fH}$, variability of moisture; $\mathrm{Ae}$, aeration of soil; $R c$, acidity; $\mathrm{Sl}$, total salt regime; $\mathrm{Ca}$, carbonate content in soil; $N t$, nitrogen content; $\mathrm{Tm}$, thermal climate; $\mathrm{Om}$, humidity; $\mathrm{C}$, cryoclimate; Kn, climate continentality; Lc, light in plant community.

The model of RDA including all soil variables was significant $\left(R_{a d j}^{2}=0.33, F=2.51, p<0.001\right)$. The forward selection procedure allowed us to select 16 soil variables, which explained $29.8 \%$ of the variability of the soil animal community $(F=3.75, \mathrm{p}<0.001)$. The list of the important soil variables included soil mechanical impedance (at the depths $0-5,25-30,35-40,45-50,50-55,60-65$, 65-70, and 75-80 cm), soil electrical conductivity, litter thickness, soil temperature, moisture, and aggregate fraction (>10, 5-7, 1-2, 0.5-1 mm). The influence of most soil properties on the soil animal community was due to their spatial structuring (Table 2). Soil structured effect is the variation of the soil animal community which is explained by the soil properties as constrained variables without extraction the effect of the other factors. When these effects are extracted (if spatial, plant and tree distance variables are used as covariates) we will obtain the pure soil effect. Almost all variation explained by soil variables was spatially structured. Accounting for dependence in model residuals using spatial filters as covariates, the majority of the soil properties' influence models were not significant at $\mathrm{P}<0.05$. The exceptions were the models of soil mechanical impedance at a depth of $45-50$ and $60-65 \mathrm{~cm}$, soil electrical conductivity, litter thickness, soil temperature and moisture. These variables presented the pure soil effect on the macrofauna community. The influence of aggregate size fractions $>10 \mathrm{~mm}$ content on the soil animal community was due to herb layer community. The distance from trees modulated the effects of humidity, temperature and aggregate size fractions 1-2 on the soil animal community. The soil mechanical impedance at a depth of $45-50 \mathrm{~cm}$, soil electrical conductivity and litter thickness influenced the soil animal community, which does not depend on other environmental regimes.
There were 48 dbMEMs-spatial variables which together explain $66.6 \%$ of the animal community variability. The forward selection procedure allowed us to select 38 variables, which explain $65.8 \%$ of the variability of the community $(F=6.12, \mathrm{p}<0.001)$.

The broad-scale variables played the greatest role in spatial variation of the soil animal community (Fig. 2). If no covariates were included, the distribution of explained variation was rightward skewed. The spatial placement of trees had a little effect on spatial variation of soil animal community. Filtering out tree distance variables as covariates had a rather minor effect on the distribution of the variation explained shape. The soil models were able to account for most of the broad-scale variation, which may be detected as a decrease in the height of black columns. The influence of herb layer vegetation was similar to the influence of soil properties, probably due to their close dependence.

Accounting for environmental factors in model residuals using soil, plant and tree distance data as covariates changed the distribution of explained variation considerably, decreasing the importance of broad-scaled dbMEMs in favour of meso- and fine-scaled dbMEMs. Also of note was the role of the evenness of the variation at different scales of the pure spatial components.

The model of RDA including 30 dbMEMs-tree distance variables was significant $\left(R_{a d j}^{2}=0.21, F=1.91, p<\right.$ $0.001)$. The forward selection procedure allowed us to select 10 variables, which explains $19.2 \%$ of the variability of the community $(F=3.47, \mathrm{p}<0.001)$. The broad-scale component of the tree structured space had the greatest influence on the soil animal community (Fig. 3). Accounting for spatial variables as the covariates significantly reduced 


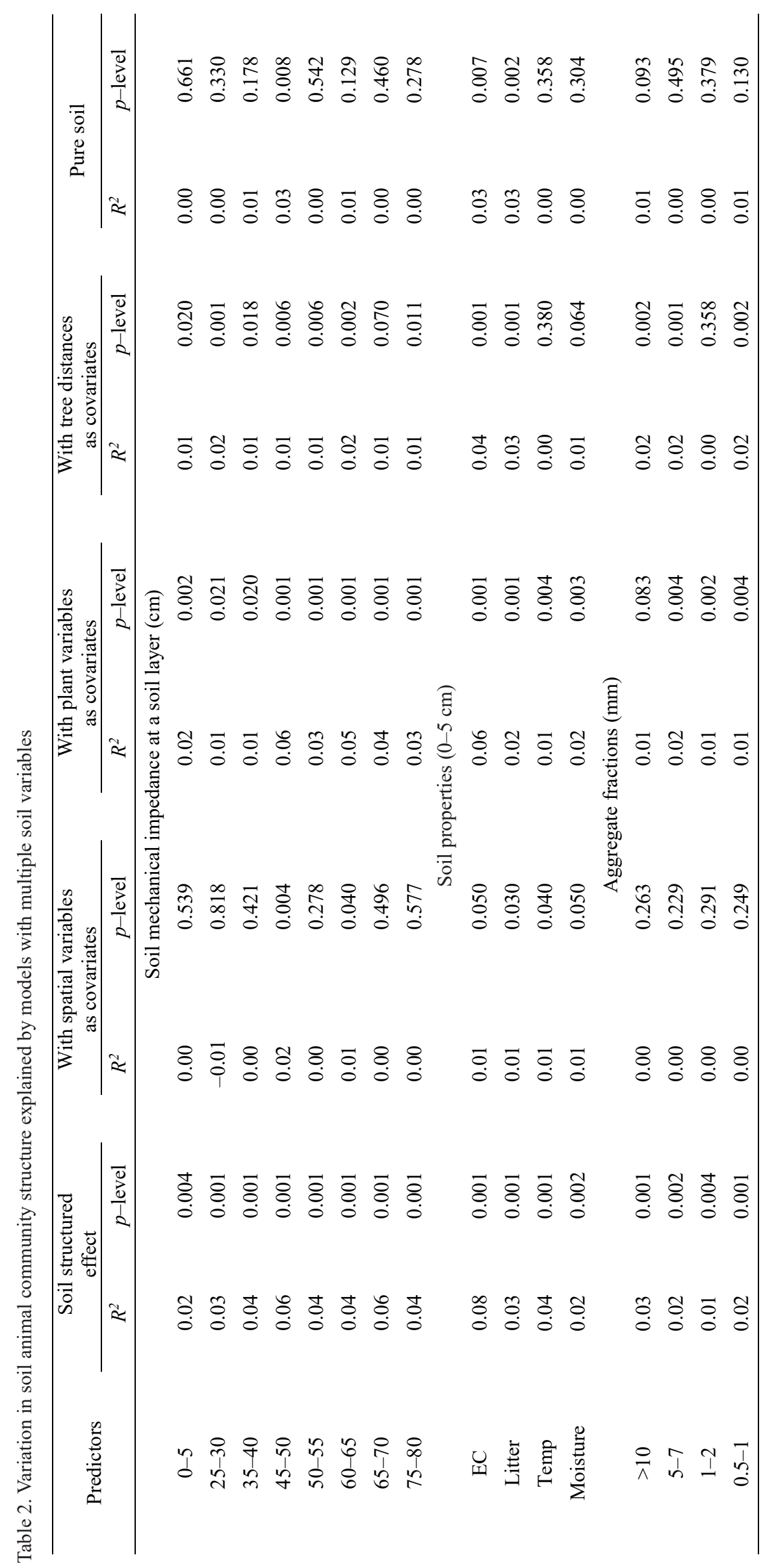



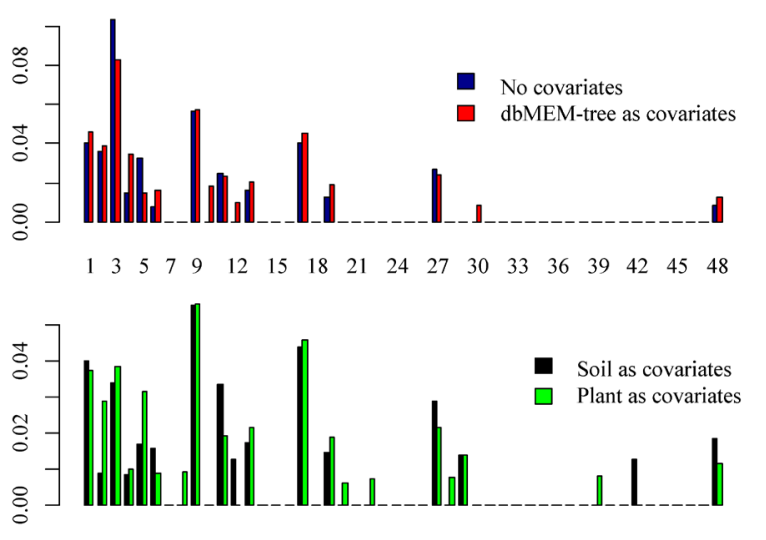

$\begin{array}{llllllllllllllllll}1 & 3 & 5 & 7 & 9 & 12 & 15 & 18 & 21 & 24 & 27 & 30 & 33 & 36 & 39 & 42 & 45 & 48\end{array}$

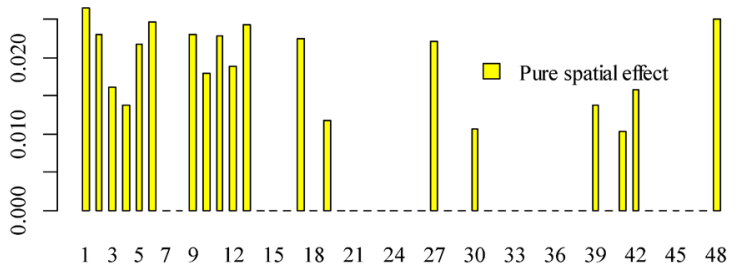

Fig. 2. Scalograms illustrating the scaling of spatial structured variation in community data (No variables as covariates, blue bars) and tree models (red bars), residuals of the soil models (black bars), plant models (green bars) and pure spatial effect (yellow bars). The value of $R_{a d j}^{2}$ is the variation explained by individual dbMEM variables. The dbMEMs are ordered decreasingly according to the scale of spatial patterns they represent ( $x$-axis is the number of dbMEM; dbMEM 1 represents the broadest scale, dbMEM 48 represents the finest scale). the level of the tree location influence on the soil animal community. Accounting for soil and the herb layer vegetation properties decreased the role of the broad-scale component and does not substantially affect either fine- or meso-scale components of tree-structured space.

The pure effect of tree structured space on the soil animal community was presented by the broad-scale and meso-scale components. The broad-scale component was indicated by endogeic (positive values) and epigeic (Lithobius lucifugus, Trachelipus rathkii, Tipula lunata) or anecic (Octodrilus transpadanus) soil animals (negative values) (Table 3 ). The meso-scale component was indicated by epigeic (positive values) and endogeic (Aporrectodea trapezoides, Athous haemorrhoidalis, Melolontha melolontha) and anecic (Octodrilus transpadanus) animals. The complex nature of the soil animal community variability depending on the distance from the nearest tree showed the interaction of tree species in their effects on soil animals (Fig. 4).

The model of RDA including 6 principal components of the herb layer community variation was significant $\left(R_{a d j}^{2}=0.20, F=5.37, p<0.001\right)$. The forward selection procedure allowed us to select 5 variables which explains $18.7 \%$ of the variability of the community $(F=$ $5.78, \mathrm{p}<0.001)$. The influence of herb layer vegetation on soil animals was strongly spatially structured (Table 4). This result follows from the fact that the accounting for spatial variables as covariates made the effect of plant community on soil invertebrates variables not statistically significant at $\mathrm{P}<0.05$. In turn, the influence of herb layer vegetation on soil animals did not depend on soil properties. The influence of the principal component 4 was re-
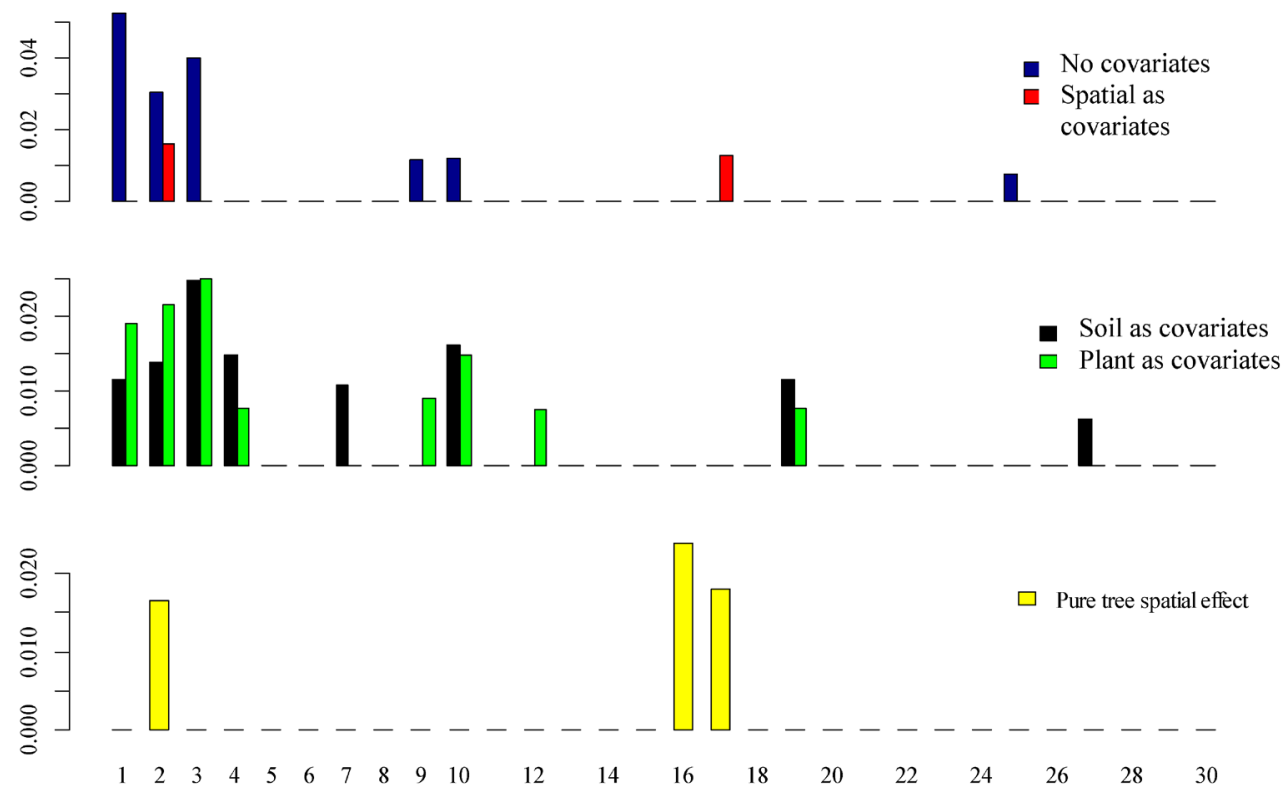

Fig. 3. Scalograms illustrating the scaling of tree structured variation in community data (No variables as covariates, blue bars) and residuals of the spatial models (red bars), soil models (black bars), plant models (green bars) and pure tree effect

(yellow bars). The value of $R_{a d j}^{2}$ is the variation explained by individual dbMEM variables. The dbMEMs are ordered decreasingly according to the scale of spatial patterns they represent (x-axis is the number of dbMEM; dbMEM 1 represents the broadest scale, dbMEM 30 the finest scale). 
Table 3. Species with the largest absolute value of the RDA-axes with broad-scale and meso-scale dbMEMs-tree variables as covariates

$\begin{array}{cc}\text { Broad-scale } & \text { Meso-scale } \\ \text { (dbMEMs-tree 2 as covariate) } & \text { (dbMEMs-tree 16 and 17 as covariates) } \\ \text { Species with the largest value of the RDA-axes } \\ \text { Cardiophorus rufipes } & \text { Rhipidia uniseriata } \\ \text { Athous haemorrhoidalis } & \text { Cochlicopa lubrica } \\ \text { Otiorhynchus ligustici } & \text { Tabanus bromius } \\ \text { Species with the smallest value of the RDA-axes } \\ \text { Octodrilus transpadanus } & \text { Thereva nobilitata } \\ \text { Tipula lunata } & \text { Aporrectodea trapezoides } \\ \text { Trachelipus rathkii } & \text { Athous haemorrhoidalis } \\ \text { Lithobius lucifugus } & \text { Melolontha melolontha } \\ \end{array}$
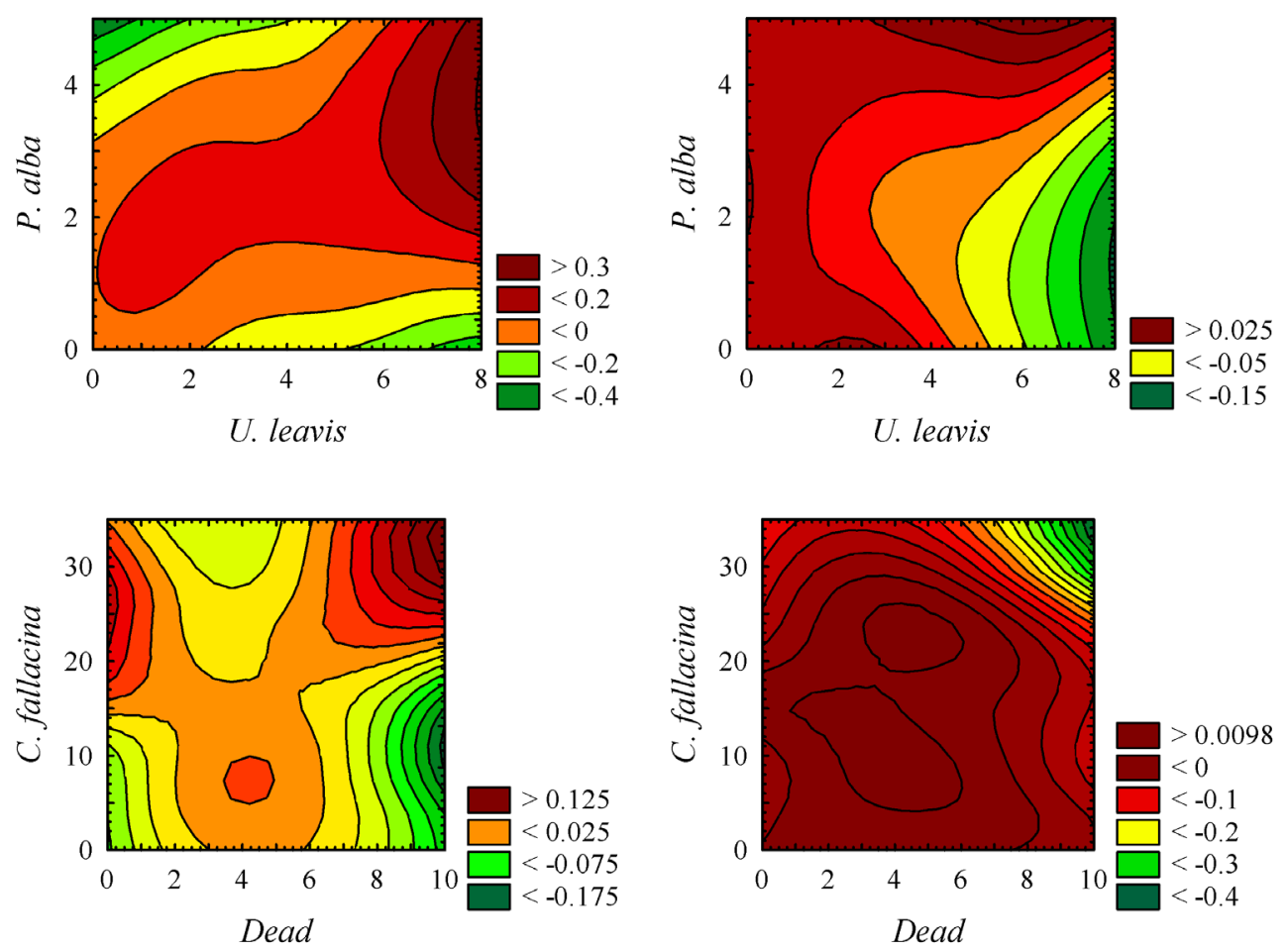

Fig. 4. The variation of the soil animal community RDA-axes with dbMEMs-tree 2 and dbMEMs-tree 16 and 17 as explanatory variables in dependence from tree distances (in meters). $x$-axis and $y$-axis - distances from the trees.

vealed as being due to the distance from tree plants. The pure herbal component that did not depend on other measured environmental properties is presented by only the principal component 5 .

The environmental factors considered all together explained $70 \%$ of variation in the community structure of soil animals (Fig. 5). The largest contribution to the variation of the soil animal community structure was made by the purely spatial component $(28.1 \%)$. The pure contribution of soil properties is significantly less $(3.5 \%)$ and pure contribution of the distance from trees $(1.1 \%)$. The contribution of herb layer community structure to varia- tion of the soil animal community was extremely small, although statistically significant $(0.6 \%)$. The spatially structured components of environment properties significantly affected the structure of the soil fauna community. The spatially structured soil properties determined 7.8\% of the variation in the community. The spatially structured component of plant communities, depending on soil properties, determined $8.1 \%$ of the variation in the community of soil animals. The spatially structured component of the tree structured space influence greatly exceeded the role of a pure tree structured component (6.2\% vs. $1.1 \%)$. 
Table 4. Variation in soil animal community structure explained by models with herb layer community variables

\begin{tabular}{|c|c|c|c|c|c|c|c|c|c|c|}
\hline \multirow{2}{*}{ Predictors } & \multicolumn{2}{|c|}{ Plants structured } & \multicolumn{2}{|c|}{$\begin{array}{c}\text { With spatial variables } \\
\text { as covariates }\end{array}$} & \multicolumn{2}{|c|}{$\begin{array}{c}\text { With soil variables } \\
\text { as covariates }\end{array}$} & \multicolumn{2}{|c|}{$\begin{array}{l}\text { With tree distances } \\
\text { as covariates }\end{array}$} & \multicolumn{2}{|c|}{ Pure plants } \\
\hline & $R^{2}$ & $p$-level & $R^{2}$ & $p$-level & $R^{2}$ & $p$-level & $R^{2}$ & $p$-level & $R^{2}$ & $p$-level \\
\hline PC 1 & 0.08 & 0.001 & 0.00 & 0.234 & 0.01 & 0.06 & 0.06 & 0.001 & 0.01 & 0.13 \\
\hline PC 2 & 0.04 & 0.001 & 0.01 & 0.099 & 0.01 & 0.012 & 0.04 & 0.001 & 0.01 & 0.123 \\
\hline PC 3 & 0.01 & 0.002 & 0.00 & 0.778 & 0.02 & 0.002 & 0.01 & 0.009 & 0.00 & 0.646 \\
\hline PC 4 & 0.03 & 0.001 & -0.01 & 0.891 & 0.01 & 0.034 & 0.00 & 0.392 & 0.00 & 0.525 \\
\hline PC 5 & 0.01 & 0.008 & 0.00 & 0.214 & 0.01 & 0.005 & 0.02 & 0.002 & 0.02 & 0.050 \\
\hline PC 6 & 0.01 & 0.010 & 0.00 & 0.550 & 0.03 & 0.001 & 0.02 & 0.001 & 0.01 & 0.168 \\
\hline
\end{tabular}
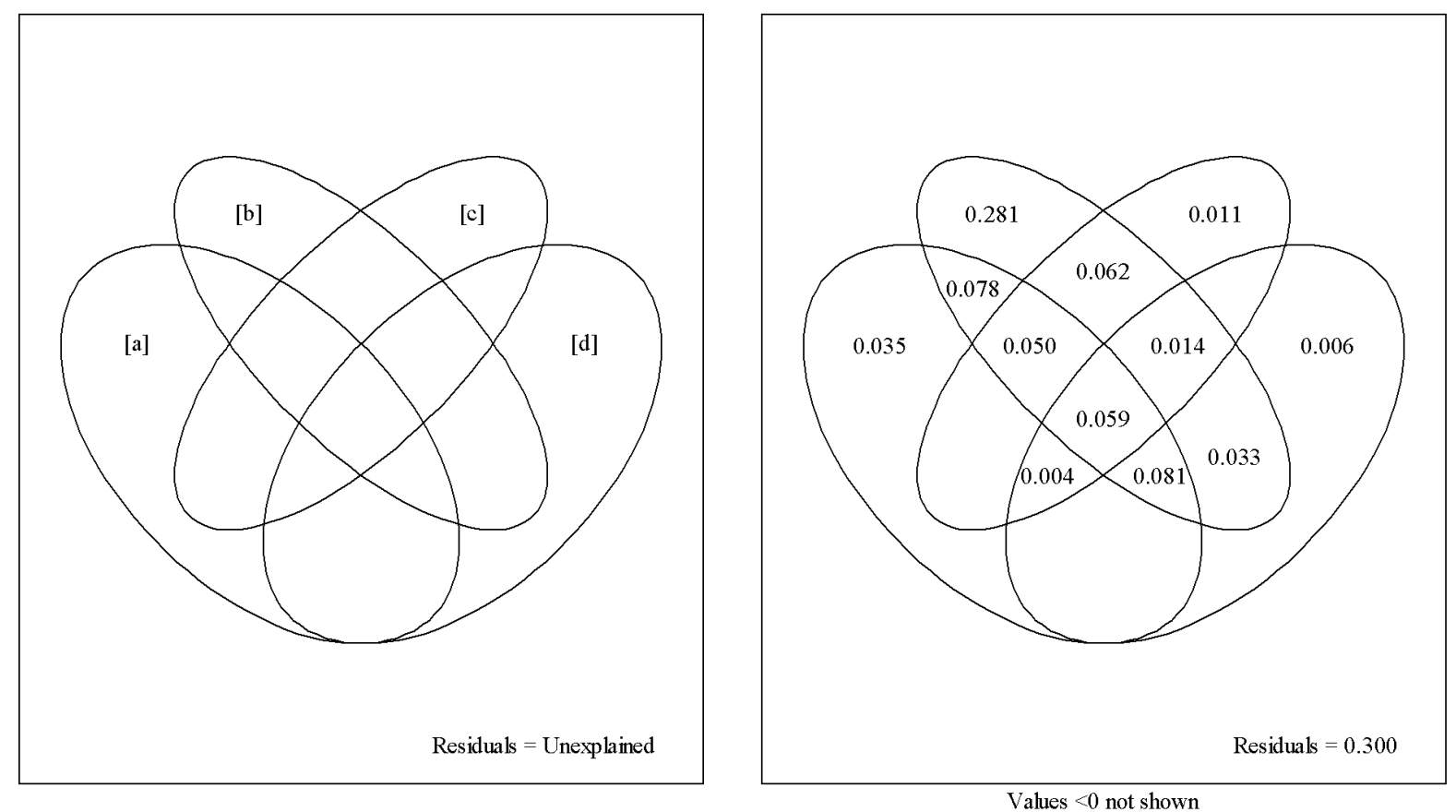

Fig. 5. Variance partitioning between spatial, soil, plant and tree distance explanatory variables.

[a] - variation explained solely by soil variables; $[\mathrm{b}]$ - variation captured by spatial (dbMEM) variables corresponds to pure space (residual spatial component); [c] - variation captured by distances from tree stems; [d] - explained solely by plant variables. The intersection of the ellipses corresponds to the variations explained by the respective sources together All the variance fractions shown are significant $(p<0.001)$.

\section{Discussion}

Non-random spatial organization of species assemblage involves the existence of at least one structuring factor, e.g. inter-specific competition and/or habitat constraints (JIMÉNES et al., 2012). The structure of animal communities may be governed by processes of a neutral nature or by environmental factors (KARUNARATNE et al., 2015). The spatial trends of any complexity for a given experimental design can be approximated by complex combinations of the dbMEMs-variables. The variation explained purely by spatial variables represents partly unmeasured environmental variables with spatial structure, and partly dispersal limitation (LEGENDRE et al., 2009). The purely spatial component is associated with the effects of a neutral nature. However, pure space patterns of the soil animal community may be not only of neutral origin but also of a biotic nature and formed as a result of the spatial structuring of the forest ecosystem trees' space due to the trees' spatial location. The purely spatial component can also be the result of unmeasured environmental factors. In this case, neutral processes are associated with fine-scale spatial patterns. The purely spatial patterns also can be induced due to structuring of space by trees. This kind of the spatial structure can also be modeled by the dbMEMs-approach. But in this case, the spatial structure is given not only by an arbitrary set of sampling points, but also by the placement of real objects of nature - trees. Plant community ordination axes may be used as quantitative characteristics of the 
impact of plants on the soil animal community (ZHUKOV et al., 2018a). Phytoindicator values allowed us to interpret these axes as gradients of the specific ecological factors.

The variability of soil properties affects the soil fauna (Berg and Bengtsson, 2007; Viketoft, 2013). Our results reveal that the herb layer in turn also affects both the soil and the soil animals directly. Soil and plants are connected by their mutual influence. The influence of the soil mechanical impedance and soil aggregate structure on the soil animal community was not statistically significant if spatial covariates were included in the models. This result shows that the effect of these soil properties on the soil animal community is spatially dependent. Obviously, in flood conditions the parent material variability of the alluvial soils is very considerable (WEBER and GoBAT, 2006), resulting in the formation of spatial trends in soil mechanical impedance and aggregate particles' composition (SAĞLAm and DeNGiZ, 2017). Duration of flooding and intensity of the sedimentation of suspended particles is a source of the spatial mosaic of alluvial soils (THомs, 2003). These spatially structured factors may have a direct impact on soil animals, which explains the spatially structured effect of the soil mechanical impedance and soil aggregate structure on the soil animal community.

The formation of soil aggregates larger than $10 \mathrm{~mm}$ can be attributed to the activity of the root system of herbaceous plants (GE et al., 2018). This explains the fact that vegetation is a source of the influence of the soil aggregate content larger than $10 \mathrm{~mm}$ on the soil animals. The forest canopy structure determines the quantity of light reaching the surface of the soil and thus variation in the temperature of the surface of the soil (SHAW and BibLE, 1996). This explains the influence of the tree stand on the effect on the animals of soil surface temperature.

The pure soil factors that do not depend on other measured environmental properties or the spatial variables include soil electrical conductivity and litter thickness. These variables cannot be excluded as being characterized by variations in the spatial component, which is not included in the frame of the experimental approach of sampling point locations. The amount of litter may change the amount of food resources and habitat characteristics. For optimal dynamic of biological processes as well as the life of soil organisms and plant roots, it is important that a sufficient supply of water and air enters the soil (PoLlÁkové et al., 2017). Litter is an important factor that determines the characteristics of the soil animal habitat. Organic matter inputs to the soil, including leaf litter, root litter and root exudates, represent the energy base of the soil food web (VERHOEF and BRUSSAARD, 1990). Our results show that these soil properties are extremely important for soil animals and allow us to estimate proportional input of soil structure, composition of herb community and spatial factors to structuring of soil macrofauna communities. Our findings revealed that the purely spatial component had the largest contribution to the variation of the soil animal community. The role of the soil properties and the distance from trees are significantly less. The significance of the herb layer was found to be extremely small.

The tree species composition can influence the dynamics of herbaceous species (BRATTON, 1976) by changing light availability (BRESHEARs et al., 1997) and enhancing the spatial heterogeneity of the soil (ANDIVIA et al., 2015). The influence of tree structured variation in soil animal community composition was found to be broadscaled. Accounting for spatial variables as the covariates significantly reduces the variation in the soil animal community explained by trees. The change in density of a mature forest caused by previous thinning may significantly influence the structure of studied communities of epigeic macrofauna when a very intensive thinning is carried out (Stašıov and SvitoK, 2014). Accounting for vegetation and soil properties reduces the role of the broad-scale component of the trees' influence. It is noted that the tree structured broad-scale component corresponds to mesoscale spatial variables. The spatial pattern in species composition of the overstorey forest stratum is significantly correlated with that of the herb layer stratum (MöLDER et al., 2008). It is obvious that the meso-scale spatial component is due to the effect of trees on soil animals. This finding confirmed our hypothesis that the placement of trees in the floodplain ecosystem leads to multiscale spatial structuring and responsible for formation of the pure spatial patterns of the soil macrofauna.

The pure trees' effect on soil and animal community is caused by broad- and meso-scale components. The impact on the soil animal community depends on the ecological characteristics of individual species. As was found in a previous investigation, for litter-dwelling animals, the most characteristic spatial patterns are on the broad- and meso-scale levels but for endogeic and anecic animals, the most significant variability is on the fine-scale level (ZHuKov et al., 2018a). Our results revealed that the effect of the tree structured broad-scale component differentiates the community of soil animals, from one side, to insect larvae (zoophages - Cardiophorus rufipes, Athous haemorrhoidalis and phytophagous - Agrotis clavis and Otiorhynchus ligustici), and on the other side - to the epigeic (Lithobius lucifugus, Trachelipus rathkii, Tipula lunata) and anecic (Octodrilus transpadanus) lifeforms. The meso-scale component differentiates the community, on the one hand, to the epigeic, and, on the other hand, - to the endogeic (Aporrectodea trapezoides, Athous haemorrhoidalis, Melolontha melolontha) and anecic (Octodrilus transpadanus). The nature of the trees' effect on soil animals is species-specific. The relative positioning of trees in the space creates a complex mosaic of ecological conditions. Thus, the structure of the forest canopy leads to vertical stratification of the soil animal community.

The influence of plant variables on the soil animal community became insignificant after accounting for spatial variables. There is no effect of soil properties on influence of vegetation on the soil animals. The effect of plant principal component 4 (thermal climate and cryoclimate) on the soil animal community is due to the forest canopy structure. The structure of the tree crowns and tree 
placement considerably affects the variation of the microclimate in the forest ecosystem. The pure plant influence on soil animals is caused by the principal component 5 (calcium carbonate content in soil and variability of moisture). Calcium deficiency in the sand floodplain soils can act as a limiting factor for the soil fauna. The spatial distribution of plants, which are the source of this element, can have an impact on soil fauna.

\section{Conclusions}

The spatial component had the largest contribution to the variation of the soil animal community. Soil, tree, and herb layer vegetation variables were revealed to be highly spatially structured. Soil variables estimated in the present investigation explained $29.8 \%$ of the variability of the soil animal community. The considerable part of the variation explained by soil properties was spatially structured. Only soil electrical conductivity and litter depth had a statistically significant effect on the soil animal community after using other environmental and spatial filters. The effect of the aggregate fraction content with size $>10 \mathrm{~mm}$ was mediated by the herbal layer. The effect of the aggregate fraction content with size 1-2 $\mathrm{mm}$ and soil surface temperature was mediated by the tree canopy structure.

The main part of the soil animal community variation explained by tree derived dbMEM variables was spatially structured. Adding spatial variables to the covariates leads to decrease in the importance of broad-scaled dbMEMs tree derived variables. The effect of the soil and plant properties on the soil animal community may be considered as partly induced by tree dependent spatial structuring. Tree induced spatial structuring consisted of two scaling components: broad-scale and meso-scale. The sensitivity of the community to the effect of these factors was ecologically specific. The tree effect was transmitted through vertical stratification of the soil animal community.

The influence of herb layer vegetation on soil animals was strongly spatially structured. The pure herbal component reflected the dependence of the soil animals on the calcium-rich plants' spatial distribution. Trees affect herb layer species which were sensitive both to temperature and nitrogen regime variation. Soil animals were influenced by this canopy effect too. These findings allow us to suggest that the spatial structures that interact with soil, plants and tree factors in shaping soil macrofauna communities have a considerable importance.

A promising direction for further research on the problem discussed here is to study the effects of tree canopy on the structuring of soil macrofauna communities in different types of forest ecosystems. The investigation of not only distance dependent impact but density dependent impact of tree distribution on soil macrofauna communities is important.

\section{Acknowledgements}

The authors are grateful to the staff of "Dniprovsko-Orilsky" Nature Reserve for their support and assistance with this research. We thank Paul Bradbeer for checking the English text and the tree anonymous reviewers for helping us to improve earlier versions of this paper.

\section{References}

Aiba, M., TaKafumi, H., Hiura, T., 2012. Interspecific differences in determinants of plant species distribution and the relationships with functional traits. Journal of Ecology, 100: 950-957. https://doi.org/10.1111/j.13652745.2012.01959.x

Andivia, E., Fernández, M., Alejano, R., Vázquez-Piqué, J., 2015. Tree patch distribution drives spatial heterogeneity of soil traits in cork oak woodlands. Annals of Forest Science, 72: 549-559. https://doi.org/10.1007/s13595015-0475-8

Bahram, M., Kohout, P., Anslan, S., Harend, H., AbarenKov, K., Tedersoo, L., 2016. Stochastic distribution of small soil eukaryotes resulting from high dispersal and drift in a local environment. The ISME Journal, 10 (4): 885-896. https://doi.org/10.1038/ismej.2015.164

Bardgett, R.D., van der Putten, W.H., 2014. Belowground biodiversity and ecosystem functioning. Nature, 515 (7528): 505-511. https://doi.org/10.1038/nature13855

Barton, P. S., Cunningham, S.A., Manning, A.D., Gibb, H., Lindenmayer, D.B., Didham, R.K., 2013. The spatial scaling of beta diversity. Global Ecology and Biogeography, 22 (6): 639-647. https://doi.org/10.1111/geb.12031

Berg, M. P., Bengtsson, J., 2007. Spatial and temporal variation in food web composition. Oikos, 116: 1789-804. https://doi.org/10.1111/j.0030-1299.2007.15748.x

Blanchet, F.G., Legendre, P., Borcard, D., 2008. Forward selection of explanatory variables. Ecology, 89 (9): 2623 2632. https://doi.org/10.1890/07-0986.1

Borcard, D., Legendre, P., 2002. All-scale spatial analysis of ecological data by means of principal coordinates of neighbour matrices. Ecological Modelling, 153: 51-68. https://doi.org/10.1016/S0304-3800(01)00501-4

BRATTON, S., 1976. Resource division in an understory herb community: responses to temporal and microtopographic gradients. The American Naturalist, 110 (974): 679-693. [cit. 2019-05-02]. www.jstor.org/stable/2459584.

Breshears, D., Rich, P., Barnes, F., Campbell, K., 1997. Overstory-imposed heterogeneity in solar radiation and soil moisture in a semiarid woodland. Ecological Applications, 7 (4): 1201-1215. https://doi.org/10.1890/1051-0761(1997)007[1201:OIHISR]2.0.CO;2

BuzuK, G. N., 2017. Phytoindication with ecological scales and regression analysis: environmental index. Bulletin of Pharmacy, 2 (76): 31-37.

Callaham, Jr., M.A., Richter, Jr., D.D., Coleman, D.C., HofMOCKel, M., 2006. Long-term land-use effects on soil invertebrate communities in Southern Piedmont soils, USA. European Journal of Soil Biology, 42 (1): S150S156. https://doi.org/10.1016/j.ejsobi.2006.06.001 
Cesarz, S., Fahrenholz, N., Migge-Kleian, S., Platner, C., SCHAEFER, M., 2007. Earthworm communities in relation to tree diversity in a deciduous forest. European Journal of Soil Biology, 43 (1): S61-S67. https://doi. org/10.1016/j.ejsobi.2007.08.003

Chang, L., Zeleny, D., Li, C., Chiu, S., Hsieh, C., 2013. Better environmental data may reverse conclusions about niche- and dispersal-based processes in community assembly. Ecology, 94: 2145-2151. https://doi. org/10.1890/12-2053.1

Chase, J.M., 2014. Spatial scale resolves the niche versus neutral theory debate. Journal of Vegetation Science, 25: 319-322. https://doi.org/10.1111/jvs.12159

Chen, B., Wise, D.H., 1999. Bottom-up limitation of predaceous arthropods in a detritus-based terrestrial food web. Ecology, 80: 761-772. https://doi.org/10.1890/00129658(1999)080[0761:BULOPA]2.0.CO;2

Chudomelová, M., ZelenÝ, D., Li, Ch.-F., 2017. Contrasting patterns of fine-scale herb layer species composition in temperate forests. Acta Oecologica, 80: 24-31. https:// doi.org/10.1016/j.actao.2017.02.003

De Cáceres, M., Legendre, P., Valencia, R., CaO, M., Chang, L.W., Chuyong, G., Kenfack, D., 2012. The variation of tree beta diversity across a global network of forest plots. Global Ecology and Biogeography, 21 (12): 1191-1202. https://doi.org/10.1111/j.14668238.2012.00770.x

Decaens, T., Dutoit, T., Alard, D., Lavelle, P., 1998. Factors influencing soil macrofaunal communities in postpastoral successions of western France. Applied Soil Ecology, 9: 361-367. https://doi.org/10.1016/S09291393(98)00090-0

DiDukH, Y.P., 2011. The ecological scales for the species of Ukrainian flora and their use in synphytoindication. Kyiv: Phytosociocentre. 176 p.

Dini-Andreote, F., Stegen, J.C., Van Elsas, J.D., Salles, J.F., 2015. Disentangling mechanisms that mediate the balance between stochastic and deterministic processes in microbial succession. Proceedings of the National Academy of Sciences of the United States of America, 112 (11): E1326-E1332. https://doi.org/10.1073/ pnas. 1414261112

Dray, S., Bauman, D., Blanchet, G., Borcard, D., Clappe, S., Guenard, G., Jombart, T., Larocque, G., LegenDRE, P., MADI, N., WAGNeR, H.H., 2018. adespatial: Multivariate Multiscale Spatial Analysis. R package version 0.3-2. https://CRAN.R-project.org/package=adespatial

Dumbrell, A. J., Nelson, M., Helgason, T., Dytham, C., FitTER, A.H., 2010. Relative roles of niche and neutral processes in structuring a soil microbial community. The ISME Journal, 4 (3): 337-345. https://doi.org/10.1038/ ismej.2009.122

Frouz, J., Prach, K., PižL, V., HÁNĚL, L., StarÝ, J., TAJovskÝ, K., Materna, J., Balík, V., KaLČík, J., Řehounková, K., 2008. Interactions between soil development, vegetation and soil fauna during spontaneous succession in post mining sites. European Journal of Soil Biology, 44: 109121. https://doi.org/10.1016/j.ejsobi.2007.09.002

Ge, Z., Fang, S., Chen, H.Y.H., Zhu, R., Peng, S., Ruan, H., 2018. Soil aggregation and organic carbon dynam- ics in poplar plantations. Forests, 9 (9): 508. https://doi. org/10.3390/f9090508

Gholami, S., Sayad, E., Gebbers, R., Schirrmann, M ., Joschro, M., Timmer, J., 2016. Spatial analysis of riparian forest soil macrofauna and its relation to abiotic soil properties. Pedobiologia, 59 (1): 27-36. https://doi. org/10.1016/j.pedobi.2015.12.003

Gholami, S., Sheikhmohamadi, B., Sayad, E., 2017. Spatial relationship between soil macrofauna biodiversity and trees in Zagros forests, Iran. Catena, 159: 1-8. https:// doi.org/10.1016/j.catena.2017.07.021.

Graefe. U., Beylich, A., 2003. Critical values of soil acidification for annelid species and the decomposer community. Newsletter on Enchytraeidae, 8: 51-55.

Hanson, C.A., Fuhrman, J.A., Horner-Devine, M.C., MartinY, J.B., 2012. Beyond biogeographic patterns: Processes shaping the microbial landscape. Nature Reviews Microbiology, 10 (7): 497. https://doi.org/10.1038/ nrmicro2795

Hooper, D.U., Vitousek, P.M., 1997. The effects of plant composition and diversity on ecosystem processes. Science, 277: 1302-1305. doi: 10.1126/science.277.5330.1302

Hunter, M.D., Price, P.W., 1992. Playing chutes and ladders: heterogeneity and the relative roles of bottom-up and top-down forces in natural communities. Ecology, 73: 724-732. https://doi.org/10.2307/1940152

IgONDOvá, E., Majzlan, O., 2015. Assemblages of ground beetles (Carabidae, Coleoptera) in peatland habitat, surrounding dry pine forests and meadows. Folia Oecologica, 42: 21-28.

Jimenez, J.J., Decaens, T., Rossi, J.P., 2006. Stability of the spatio-temporal distribution and niche overlap in neotropical earthworm assemblages. Acta Oecologica, 30: 299-311. https://doi.org/10.1016/j.actao.2006.06.008

JimÉneZ, J.J., DeCaËns, T., Rossi, J.-P., 2012. Soil environmental heterogeneity allows spatial co-occurrence of competitor earthworm species in a gallery forest of the Colombian "Llanos". Oikos, 121: 915-926. https://doi. org/10.1111/j.1600-0706.2012.20428.x

Jones, M.M., TuOmisto, H., Clark, D.B., Olivas, P., 2006. Effects of mesoscale environmental heterogeneity and dispersal limitation on floristic variation in rainforest ferns. Journal of Ecology, 94: 181-195. https://doi. org/10.1111/j.1365-2745.2005.01071.x

Karunaratne, S., Singh, B., Robinson, L., Campbell, C., YaO, H., Powell, J., 2015. Deterministic processes vary during community assembly for ecologically dissimilar taxa. Nature Communications, 6 (1): 1-10. https://doi. org/10.1038/ncomms9444

KInG, A. W., With, K. A., 2002. Dispersal success on spatially structured landscapes: when do spatial pattern and dispersal behavior really matter? Ecological Modelling, 147 (1): 23-39. https://doi.org/10.1016/S03043800(01)00400-8.

KrIvolutsKy, D.A., 1994. Pochvennaja fauna $v$ jekologicheskom kontrole [Soil fauna in ecological control]. Moscow: Nauka. 240 p.

Lavelle, P., Senapati, B., Barros, E., 2003. Soil macrofauna. In Schroth, G., Sinclair, F.L. (eds). Trees, crops and soil fertility: concepts and research methods. Wallingford: CAB International, 2003, p. 303-323. 
LAZORÍk, M., Kula, E., 2015. Impact of weather and habitat on the occurrence of centipedes, millipedes and terrestrial isopods in mountain spruce forests. Folia Oecologica, 42: 103-112.

Legendre, P., Borcard, D., Peres-Neto, P.R., 2005. Analyzing beta diversity: Partitioning the spatial variation of community composition data. Ecological Monographs, 75: 435-450. https://doi.org/10.1890/05-0549

Legendre, P., Gallagher, E.D., 2001. Ecologically meaningful transformations for ordination of species. Oecologia, 129 (2): 271-280. https://doi.org/10.1007/ s004420100716

Legendre, P., LegENDRE, L., 2012. Numerical ecology. Third English edition. Amsterdam, NL: Elsevier Science. 1006 p.

Legendre, P., Mi, X., Ren, H., MA, K., Yu, M., Sun, I.-F., He, F., 2009. Partitioning beta diversity in a subtropical broadleaved forest of China. Ecology, 90: 663-674. https://doi.org/10.1890/07-1880.1

Lososová, Z., Šmarda, P., Chytrú, M., Purschke, O., PyšEk, P., SÁdlo, J., TichÝ, L., Winter, M., 2015. Phylogenetic structure of plant species pools reflects habitat age on the geological time scale. Journal of Vegetation Science, 26: 1080-1089. https://doi:10.1111/jvs.12308

Mathieu, J., Grimaldi, M., Jouquet, P., Rouland, C., Lavelle, P., Desjardins, T., Rossi, J. P., 2009. Spatial patterns of grasses influence soil macrofauna biodiversity in Amazonian pastures. Soil Biology \& Biochemistry, 41: 586-593. https://doi:10.1016/j.soilbio.2008.12.020

Mathieu, J., Rossi, J.P., Grimaldi, M., Mora, P., Lavelle, P., Rouland, C., 2004. A multi-scale study of soil macrofauna biodiversity in Amazonian pastures. Biology and Fertility of Soils, 40: 300-305. https://doi.org/10.1007/ s00374-004-0777-8

Mitchell, R.J., Campbell, C.D., Chapman, S.J., Osler, G.H.R., Vanbergen, A.J., Ross, L.C., Cameron, C.M., COLE, L., 2007. The cascading effects of birch on heather moorland: a test for the top-down control of an ecosystem engineer. Journal of Ecology, 95: 540-554. https://doi: 10.1111/j.1365-2745.2007.01227.x

Mölder, A., Bernhardt-Römermann, M., Schmidt, W., 2008. Herb-layer diversity in deciduous forests: raised by tree richness or beaten by beech? Forest Ecology and Management, 256 (3): 272-281. https://doi.org/10.1016/j. foreco.2008.04.012

Oksanen, J., Blanchet, F.G., Kindt, R., Legendre, P., Minchin, P.R., O'Hara, R.B., Simpson, G.L., Solymos, P., Stevens, M.H.H., Wagner, H., 2018. Community Ecology Package. R package version 2.5-2. [cit.2019-0403]. https://CRAN.R-project.org/package=vegan

Peay, K.G., Garbelotto, M., Bruns, T.D., 2010. Evidence of dispersal limitation in soil microorganisms: Isolation reduces species richness on mycorrhizal tree islands. Ecology, 91 (12): 3631-3640. https://doi.org/10.1890/092237.1

Polláková, N., ŠmanskÝ, V., Jonczak, J., 2017. Characteristics of physical properties in soil profiles under selected introduced trees in the Nature Reserve Arboretum Mlyňany, Slovakia. Folia Oecologica, 44: 78-86. https:// doi.org/10.1515/foecol-2017-0010
Ponsard, S., Arditi, R., Jost, C., 2000. Assessing top-down and bottom-up control in a litter-based soil macroinvertebrate food chain. Oikos, 89: 524-540. https://doi. org/10.1034/j.1600-0706.2000.890312.x

Powell, J.R., Karunaratne, S., Campbell, C.D., Yao, H., Robinson, L., Singh, B.K., 2015. Deterministic processes vary during community assembly for ecologically dissimilar taxa. Nature Communications, 6: 8444. https:// doi.org/10.1038/ncomms9444

Power, M. E., 1992. Top-down and bottom-up forces in food webs: do plants have primacy? Ecology, 73: 733-746. doi: $10.2307 / 1940153$

RAO, C.R., 1964. The use and interpretation of principal component analysis in applied research. Sankhyā: The Indian Journal of Statistics. Series A, 26: 329-358. [cit. 201904-19]. https://www.jstor.org/stable/25049339

SAEtre, P., 1999. Spatial patterns of ground vegetation, soil microbial biomass and activity in a mixed sprucebirch stand. Ecography, 22: 183-192. https://doi. org/10.1111/j.1600-0587.1999.tb00467.x

SAĞLAM, M., DengIZ, O., 2017. Spatial variability of soil penetration resistance in an alluvial delta plain under different land uses in middle Black Sea Region of Turkey. Archives of Agronomy and Soil Science, 63 (1): 60-73. https://doi.org/10.1080/03650340.2016.1178386

SCHEU, S., SCHAEFER, M., 1998. Bottom-up control of the soil macrofauna community in a beechwood on limestone: manipulation of food resources. Ecology, 79: 1573-1585. https://doi.org/10.1890/0012-9658(1998)079[1573:BUC OTS]2.0.CO;2

Shaw, D.C., Bible, K., 1996. An overview of forest canopy ecosystem function with reference to urban riparian systems. Northwest Science, 70: 1-5.

Stašiov, S., Svitok, M., 2014. The influence of stand density on the structure of centipede (Chilopoda) and millipede (Diplopoda) communities in the submountain beech forest. Folia Oecologica, 41: 195-201.

Stegen, J.C., Lin, X., Fredrickson, J.K., Chen, X., KenNedy, D.W., Murray, C.J., KonopKa, A., 2013. Quantifying community assembly processes and identifying features that impose them. The ISME Journal, 7 (11): 2069. https://doi.org/10.1038/ismej.2013.93

Tномs, M. C., 2003. Floodplain-river ecosystems: lateral connections and the implications of human interference. Geomorphology, 56: 335-349. https://doi.org/10.1016/ S0169-555X(03)00160-0

Tian, G., Olimah, J.A., Adeoye, G.O., Kang, B.T., 2000. Regeneration of earthworm populations in a degraded soil by natural and planted fallows under humid tropical conditions. Soil Science Society of America Journal, 64 (1): 222-228. doi: 10.2136/sssaj2000.641222x

Vadunina, A.F., Korchagina, S.A., 1986. Metody issledovaniya fizicheskikh svoystv pochv [Methods for research of physical properties of the soil]. Moscow: Agropromizdat. $416 \mathrm{p}$.

Verhoef, H.A., BrussaARd, L., 1990. Decomposition and nitrogen mineralisation in natural and agro-ecosystems: the contribution of soil animals. Biogeochemistry, 11: 175-211. https://doi.org/10.1007/BF00004496 
Viketoft, M., 2013. Determinants of small-scale spatial patterns: importance of space, plants and abiotics for soil nematodes. Soil Biology and Biochemistry, 62: 92-98. https://doi.org/ 10.1016/j.soilbio.2013.03.012

Warren, M.W., Zou, X., 2002. Soil macrofauna and litter nutrients in three tropical tree plantations on a disturbed site in Puerto Rico. Forest Ecology and Management,170:161-171.https://doi.org/10.1016/S03781127(01)00770-8

Weber, G.B., Gobat, J.M., 2006. Identification of faces models in alluvial soil formation: The case of a Swiss alpine floodplain. Geomorphology, 74: 181-195. http://dx.doi. org/10.1016/j.geomorph.2005.07.016

Westhoff, V., van der MaArel, E., 1978. The Braun-Blanquet approach. In WhitTAKER, R.H. (eds). Classification of plant communities. The Hague: Junk, p. 289-399.

Zadorozhnaya, G.A., Andrusevych, K.V., Zhukov, O.V., 2018. Soil heterogeneity after recultivation: ecologi- cal aspect. Folia Oecologica, 45: 46-52. https://doi.org/ 10.2478/foecol-2018-0005

Zhukov, O., Kunah, O., Dubinina, Y., Novikova, V., 2018 a. The role of edaphic, vegetational and spatial factors in structuring soil animal communities in a floodplain forest of the Dnipro river. Folia Oecologica, 45: 8-23. https:// doi.org/10.2478/foecol-2018-0002

Zhukov, O., Kunah, O., Dubinina, Y., NoviKova, V., $2018 \mathrm{~b}$. The role of edaphic and vegetation factors in structuring beta diversity of the soil macrofauna community of the Dnipro river arena terrace. Ekológia (Bratislava), 37 (3): 301-327. https://doi.org/10.2478/eko-2018-0023

Received June 9, 2019 Accepted September 28, 2019 